\title{
Pattern sensitive epilepsy: a case report
}

\author{
J . KOGEOR GOS, R. A. HENSON, A N D D. F. SCOT T \\ From the Section of Neurological Sciences, The London Hospital, London
}

SUMMARY A child with pattern sensitive epilepsy is reported. She had both absences and generalised seizures. The latter occurred spontaneously but the former followed concentration on patterned materials. These self-induced seizures appeared to have an affective component. The EEG showed generalised atypical spike and wave discharges both in the resting state and during intermittent photic and pattern stimulation. The patient responded to sodium valproate.

Pattern sensitive epilepsy is the tendency to epileptic attacks on viewing particular patterns. It is a rare form of reflex seizure disorder, and was first described by Bickford et al. (1953). There have been few reports subsequently, but detailed studies have been carried out by Chatrian et al. (1970a, b) and Forster (1977). The disorder is generally regarded as a type of photosensitive epilepsy, but only $5 \%$ of patients with photosensitive fits also have the pattern sensitive type (Bickford and Klass, 1969). Furthermore, the underlying neurophysiological mechanism is probably not identical in the two conditions (Wilkins et al., 1975).

The present patient was studied because of the rarity of the disorder and because she had the ability to provoke attacks herself.

\section{Case report}

A 10 year old girl (DP) was referred with intractable epilepsy. At the age of three years she started having spells in which she would suddenly become unresponsive and was noted to be stiff. These attacks, which were variable in duration, occurred several times a day, and generally lasted no more than a few seconds. At the age of 5 years one attack was followed by total loss of consciousness and twitching, predominantly on the right side of the face and in the right limbs. The attack continued for about 30 minutes and was terminated by an intravenous injection of diazepam. At that time clinical examination showed no abnormality except for transient extensor plantar responses. Routine blood chemistry and

\footnotetext{
Address for reprint requests: Dr D. F. Scott, Section of Neurological Sciences, The London Hospital, London E1 1 BB.

Accepted 21 December 1978
}

haematology were normal. Her EEG some days later showed a symmetrical abnormality consisting of generalised high voltage polyspike or polyspike and slow wave complexes. There were also bursts of theta activity at four to six cycles per second. Background activity was said to be within normal limits.

The patient's fits continued but were more often of major type, with generalised tonic-clonic seizures associated with tongue biting and urinary incontinence. They were followed by a period of deep sleep and subsequent confusion. Further EEGs were similar to the initial tracing.

More recently, the patient was seen by one of us (RAH) who recognised the pattern sensitive component of her epilepsy. At this time the attacks occurred invariably while the girl was looking at patterned materials of various sorts, including net curtains with the sun shining through and bed covers. The patterns were usually of a geometric type with parallel or crossing lines. There was a consistent deliberate effort on the part of the patient to seek out and look at such materials, despite dissuasion by her mother who thought that the patient derived pleasure from eliciting the fits. The child could invariably produce attacks by concentrating on the pattern for 15 to 20 minutes. Furthermore, despite the removal of such materials from the home the patient was still able to provoke attacks by looking at the fringes of the family's new plain curtains. When her mother noticed the girl staring intently at these curtains she would rush and "shake her up", which would avert or abort a seizure. Few attacks occurred at school or while she was out.

The patient was born at term after a normal pregnancy and delivery. There were no previous 
significant illnesses. Her early development was normal but since her attacks began at the age of three years she had become increasingly overactive. Later, learning difficulties were recognised, and she was transferred to a special school which she currently attends. Her performance there is poor, but she presents no particular behavioural problems. There is no family history of epilepsy, and her two brothers aged 12 and 5 years are healthy.

On examination the patient was a lively girl without neurological or other signs of physical disease. Psychometric testing (WISC) yielded an intelligence quotient on the performance scale of 57. Assessment of verbal ability was not possible because of poor cooperation.

\section{ELECTROENCEPHALOGRAPHY}

The EEG examination was carried out with a 16 channel Elema Schönander EEG apparatus using pad electrodes placed according to the $10 / 20$ system. The recordings were made in the resting state, with hyperventilation and during photic stimulation (flash range tested two to 30 flashes per second) and pattern stimulation. The latter was done in two ways, first with patterns consisting of black sharply defined parallel lines separated by $2-3 \mathrm{~mm}$ set on a white background. These were the patterns used by Wilkins et al. (1975). They were held in front of the child at a distance of $610 \mathrm{~mm}$. Secondly, materials such as net curtaining were either given to the patient to look at or were held in front while illuminated from behind.

In the resting state the EEG showed occasional bursts of very high voltage generalised atypical spike and wave complexes usually lasting 1-2 seconds (Fig. 1). In addition there were some less well-defined bursts of slow activity. Overbreathing was associated with a normal response. Photic
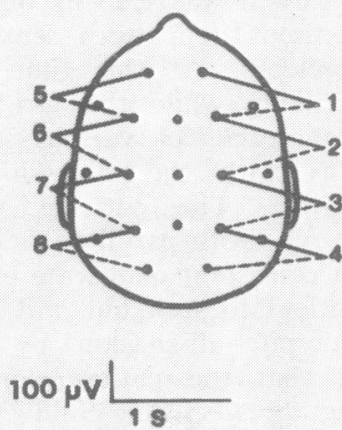

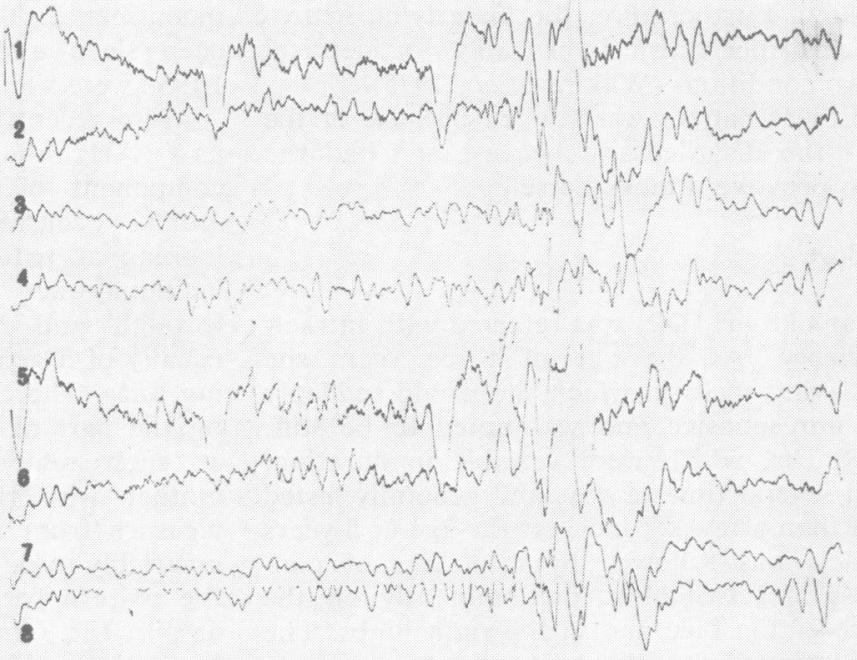

Fig. 1 Sample of EEG taken in the resting state with eyes closed. The background activity is irregular and alpha activity is poorly sustained and interspersed with theta waves. A sudden high voltage brief generalised burst of atypical spike and wave complexes appears without clinical accompaniment. This type of pattern was repeated from time to time during the EEG. Time constant $0.3 \mathrm{~s}, \mathrm{HF}$ filter setting $70 \mathrm{~Hz}$. 

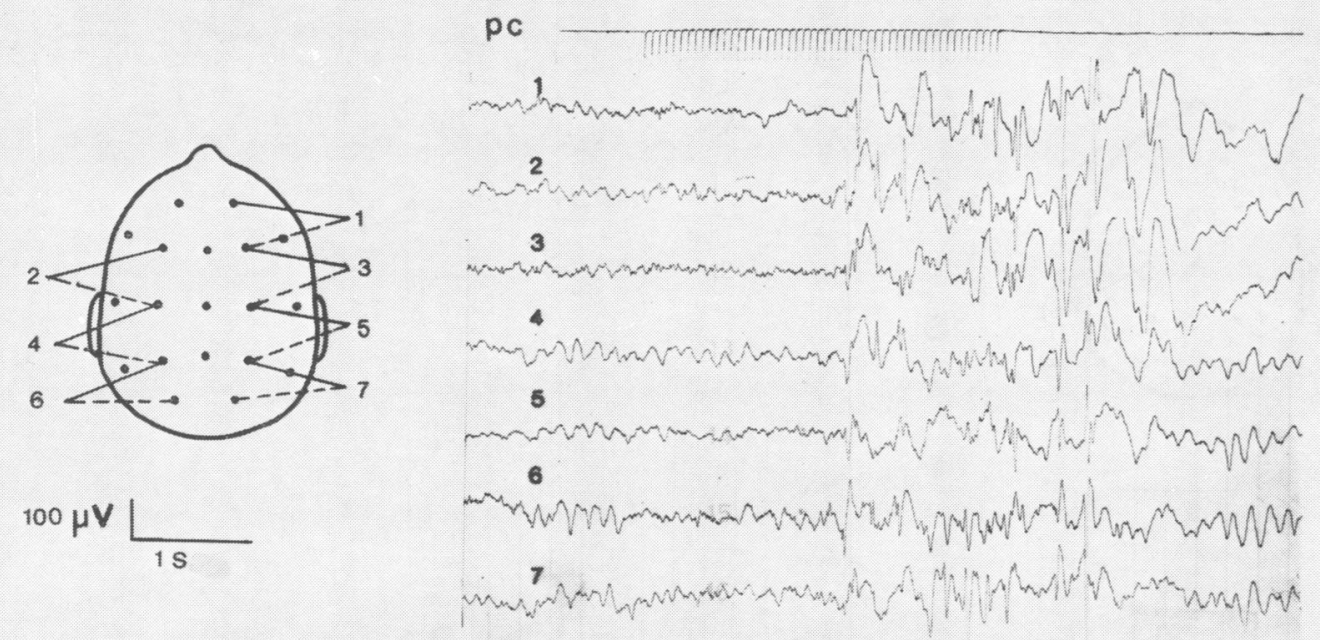

Fig. 2 Sample of the EEG during photic stimulation. With the flash rate of 18 per second there was a sudden high voltage burst of spikes and complexes which were generalised and persisted after the flashes had been concluded. This pattern was repeated at a wide range of flash frequencies (11-23 flashes/ second). Time constant $0.3 \mathrm{~s}, \mathrm{HF}$ filter setting $70 \mathrm{~Hz}$.

stimulation at flash frequencies from 11-23 per second elicited similar but more prolonged runs of atypical spike and wave complexes to those noted in the resting record (Fig. 2). Minor transient clinical changes were noted with some of these, namely blankness of facial expression and eyelid fluttering, with variable unresponsiveness.

Pattern stimulation also elicited high voltage atypical generalised spike and wave discharges (Fig. 3). When the lined patterns were used, more prolonged bursts were elicited with the horizontal rather than the vertical orientation and during movement from vertical to horizontal positions. On the occasion that she was tested systematically the child was particularly uncooperative-for example, she was observed through the net curtaining and most of the time she did not concentrate. Then suddenly her eyes fixated, a burst of atypical spike and wave discharge was seen at once in the EEG, and she looked vacant.

\section{TREATMENT}

The patient was treated with a variety of anticonvulsants. None was effective until sodium valproate (200 mg three times a day) was given. She has now been seizure-free for five months.

\section{Discussion}

By far the most impressive finding was the girl's ability to induce seizures at will with pattern stimulation, thus making her a potentially suitable model for detailed study. However, she was insufficiently cooperative. This may have contributed to her low score on the intelligence tests, which-on the basis of behaviour and speech development-would appear to be an under- 

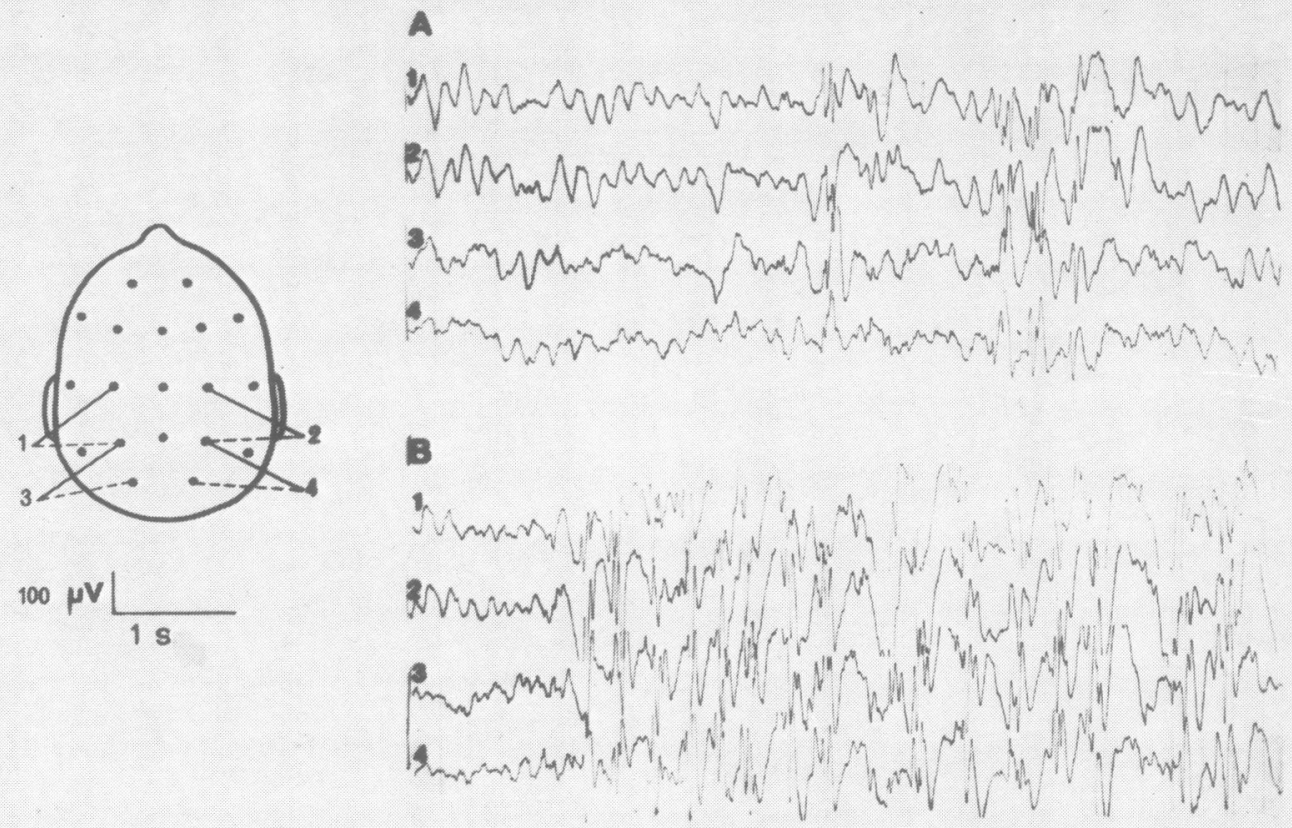

Fig. 2 Two samples of EEG during viewing of a striped pattern. In trace A, the pattern was vertically orientated. Note the sudden brief burst of spikes and complexes. In the lower trace $(B)$ viewing of the horizontal stripes produced a similar but more prolonged discharge with more profuse spikes. There were often some clinical accompaniments, mainly eyelid fluttering, and/or a variable degree of unresponsiveness. Only the posterior channels are illustrated as the discharge there is of lower voltage and the components making up the discharge can be seen more clearly. Time constant $0.3 \mathrm{~s}, \mathrm{HF}$ filter setting $70 \mathrm{~Hz}$.

estimate. Her deliberate seeking out of patterns to elicit seizures is in keeping with earlier reports of self-induced seizures by certain photosensitive subnormal children (Sherwood, 1962). In our patient, patterned material appeared to have an attraction for her, and her mother considered the attacks as being in some way pleasurable. On the other hand, the greater liability to have seizures at home than elsewhere may reflect the involvement of additional conditioning factorsfor example, her mother's immediate concern, or the lesser amount of mental stimulation at home than at school. The former could conceivably reinforce the attacks while the latter is in keeping with observations that mental activity in general, with the associated high level of arousal, favours elevation of the seizure threshold (Carels,
1965). In this context, it is of note that more fits occurred during the weekends, and the mother was convinced that this was because of "boredom".

The genetic basis of the EEG with bursts of generalised bisynchronous spike and wave complexes is well known (Metrakos and Metrakos, 1961), and there have been reports of both familial photosensitivity (Davidson and Watson, 1956) and pattern sensitivity (Chatrian et al., 1970a, b). We, therefore, took the opportunity to investigate the patient's brothers. Their EEGs were normal, even during pattern stimulation.

Movement of the patterns produced EEG discharges, a phenomenon that we have seen also in other photosensitive individuals who thus appear also to be pattern sensitive. The orientation 
of the striped material, as noted by Chatrian et al. $(1970 \mathrm{a}, \mathrm{b})$, was also important. In the present patient horizontal lines were more effective for eliciting discharge than those with a vertical orientation. Whether this relates to the elegant demonstration of directionally sensitive cortical cells in the cat and the monkey (Hubel and Wiesel, 1962, 1968 ) is speculative.

Finally, a notable feature was the patient's satisfactory response to sodium valproate.

We would like to thank Dr Arnold Wilkins for his encouragement and for providing us with the striped patterns used in his studies, and also the technicians for their help in obtaining a satisfactory recording from a restive child.

\section{References}

Bickford, R. G., Daly, D., and Keith, H. M. (1953). Convulsive effects of light stimulation in young children. American Journal of Diseases of Childhood, 86, 170-183.

Bickford, R. G., and Klass, D. W. (1969). Sensory precipitation and reflex mechanisms. In Basic Mechanisms of the Epilepsies. Edited by $\mathrm{H}$. M. Jasper, A. A. Ward, and A. Pope. Churchill: London.

Carels, G. (1965). Facilitation et inhibition des paroxysmes électroencéphalographiques induits par la stimulation lumineuse intermittente. Electroencephalography and Clinical Neurophysiology, 18, 415-418.
Chatrian, G. E., Lettich, E., Miller, L. H., and Green, J. R. (1970a). Pattern sensitive epilepsy. Part 1. An electrographic study of its mechanisms. Epilepsia, 11, 125-149.

Chatrian, G. E., Lettich, E., Miller, L. H., Green, J. R., and Kupfer, C. (1970b). Pattern sensitive epilepsy. Part 2. Clinical changes, tests of responsiveness and motor output, alterations of evoked potentials and therapeutic measures. Epilepsia, 11, 151-177.

Davidson, S., and Watson, C. W. (1956). Hereditary light sensitive epilepsy. Neurology (Minneapolis), 6, 235-261.

Forster, F. M. (1977). Reflex Epilepsy, Behavioral Therapy and Conditional Reflexes. Charles C. Thomas: Springfield, Illinois.

Hubel, D. H., and Wiesel, T. N. (1962). Receptive fields, binocular interaction and functional architecture in the cat's visual cortex. Journal of Physiology, 160, 106-154.

Hubel, D. H., and Wiesel, T. N. (1968). Receptive fields and functional architecture of monkey striate cortex. Journal of Physiology, 195, 215-243.

Metrakos, K., and Metrakos, J. D. (1961). Genetics of convulsive disorders 11. Genetic and electroencephalographic studies in centrencephalic epilepsy. Neurology (Minneapolis), 11, 474-483.

Sherwood, S. L. (1962). Self-induced epilepsy. Archives of Neurology (Chicago), 6, 49-65.

Wilkins, A. J., Andermann, F., and Ives, J. (1975). Stripes, complex cells and seizures. An attempt to determine the locus and nature of the trigger mechanism in pattern-sensitive epilepsy. Brain, 98, 365-380. 